\title{
Activation of Wnt signaling inhibits the pro-apoptotic role of Notch in gastric cancer cells
}

\author{
HONG LI ${ }^{1,2}$, JUAN MO ${ }^{2}$, GUIZHI JIA ${ }^{2}$, CHAO LIU $^{2}$, ZHIDONG LUAN $^{2}$ and YIFU GUAN ${ }^{1}$ \\ ${ }^{1}$ Department of Biochemistry and Molecular Biology, China Medical University, Shenyang, Liaoning 110001; \\ ${ }^{2}$ Department of Biochemistry and Molecular Biology, Liaoning Medical University, Jinzhou, Liaoning 121000, P.R. China
}

Received July 29, 2012; Accepted December 4, 2012

DOI: $10.3892 / \mathrm{mmr} .2013 .1412$

\begin{abstract}
Notch and Wnt signaling play critical roles in the regulation of development and diseases. Several studies have previously reported that Notch may be a therapeutic target in the treatment of various types of human cancer. In this study, we report that activation of Notch1 inhibits the proliferation of BGC-823 gastric cancer cells. However, the activation of the Wnt/ $\beta$-catenin signaling pathway promotes the growth of BGC-823 cells. Furthermore, the combinational activation of the two signaling pathways promotes the proliferation of BGC-823 cells. These data suggest that the activation of Wnt signaling overcomes the pro-apoptotic role of Notch in BGC-823 gastric cancer cells.
\end{abstract}

\section{Introduction}

Cancer develops as a result of multiple genetic and epigenetic alterations. Functional imbalances between oncogenes and tumor suppressor genes have been identified in most types of cancer, including gastric cancer (1). Better knowledge of the changes in gene expression that occur during gastric carcinogenesis may lead to improvements in diagnosis, treatment and prevention of gastric cancer (2). Increasing evidence shows that there are disorders of signaling pathways and disequilibria between oncogenes and tumor suppressor genes in the occurrence and development of gastric cancer $(3,4)$. The homeostatic self-renewal of the stomach depends on a complex interplay between processes involved in cell proliferation, differentiation, migration, adhesion and cell death (5). This panoply of cellular responses is coordinated by a relatively small number of highly conserved signaling pathways, which include the

Correspondence to: Professor Yifu Guan, Department of Biochemistry and Molecular Biology, China Medical University, 92 Bei Er Road, Heping, Shenyang, Liaoning 110001, P.R. China E-mail: yfguan55@sina.com

Abbreviations: MTT, 3-(4,5-dimethylthiazol-2-yl)-2,5-diphenyltetrazolium bromide

Key words: BGC-823, Notch1, Wnt/ $\beta$-catenin, cell proliferation, gastric cancer bone morphogenetic protein (BMP) $(6,7)$, Sonic Hedgehog (8), Notch (9) and Wnt (10) signaling pathways. Deregulation of these pathways may lead to pathological conditions, such as cancer. This notion is particularly well-illustrated by the role of the Notch and Wnt pathway in the gastric mucosa cells (11).

The Notch signaling pathway is a highly conserved signaling system in mammals, which has been found to play central roles in stem cell maintenance, cell fate decisions, as well as cancer in humans $(12,13)$. Notch receptors are single-span membrane proteins (Notch1-4 in mammals). The ligands for Notch are similar but smaller single-pass transmembrane proteins, consisting of three $\delta$-like proteins (DLL-1, -3 and -4) and two Jagged proteins (JAG-1 and -2) $(14,15)$. Binding to Notch by ligand on an adjacent cell triggers two enzymatic cleavages of Notch, extracellularly by an $\alpha$-secretase (a disintegrin and metalloprotease ADAM-10 and ADAM-17) and intracellularly by the $\gamma$-secretase/presenilin complex. The liberated Notch intracellular domain (NICD) then travels to the nucleus, displaces corepressors from CBF1/ Suppressor of hairless/LAG-1 (CSL) transcription factors, and recruits coactivators such as histone acetyl-transferase and Mastermind-like to activate downstream target genes such as the Hes and Hey gene families (16-18). A number of relevant studies have showed that the expression levels of the Notch signaling pathway components change in gastric cancer tissues $(9,12)$. However, there is not a final conclusion about whether it plays a cancer-suppressor or a cancer-promoting role on the occurrence and development of gastric cancer.

The classic Wnt/ $\beta$-catenin signaling pathway is also known to play a critical role on cell proliferation and homeostasis. In the absence of Wnt signals, free cytoplasmic $\beta$-catenin is actively targeted for degradation. This is accomplished by glycogen synthase kinase-3 $\beta$ (GSK-3 $\beta$ ) and two scaffolding proteins, the tumor suppressors adenomatous polyposis coli (APC) and Axin/Axin2, in the so-called destruction complex. Thus, $\beta$-catenin is not able to accumulate excessively (19). The binding of Wnt ligands to corresponding frizzled receptors induces the excessive accumulation of $\beta$-catenin in the cytoplasm $(20,21)$. Then, the $\beta$-catenin translocates into the nucleus and binds to the lymphoid enhancer factor (LEF)/T cell factor (TCF) families and activates downstream target genes such as c-Myc and cyclin D1 $(22,23)$. Previous studies have demonstrated that aberrant Wnt/c-Myc-catenin signaling is detected in a wide variety of human tumors, including breast 
cancer, melanoma and colon cancer (24-26). Sergio and Kalaska (27) also confirmed that the expression changes of the Wnt/ $/$-catenin signaling pathway occur in gastric cancer tissues, as well as the correlation with clinical stages and the degrees of differentiation of gastric cancer.

In the present study, we co-activated the Notch and Wnt signaling in BGC-823 human gastric cancer cells and investigated the effects of this co-activation on the proliferation of tumor cells and the possible underlying mechanism.

\section{Materials and methods}

Cell line and culture. Human gastric carcinoma BGC-823 cells (China Center for Type Culture Collection, Wuhan University, Hubei, China) were cultured in RPMI-1640 medium (Gibco, Carlsbad, CA, USA) supplemented with $10 \%$ fetal bovine serum (Sigma, St. Louis, MO, USA), $100 \mathrm{U} / \mathrm{ml}$ penicillin and $100 \mu \mathrm{g} / \mathrm{ml}$ streptomycin. All the cells were cultured in a humidified environment $\left(37^{\circ} \mathrm{C}\right.$ and $\left.5 \% \mathrm{CO}_{2}\right)$. BGC-823 cells were treated using Notch1 signaling pathway activator doxycycline (Promega, Madison, WI, USA) and Wnt/ $\beta$-catenin signaling pathway activation agent $\mathrm{LiCl}$ (Amresco, Solon, $\mathrm{OH}$, USA) for up to $48 \mathrm{~h}$.

Western blot analysis. Cells were lysed using RIPA (1\% SDS, $5 \%$ sodium deoxycholate, $1 \%$ NP-40, $0.1 \%$ PMSF) and protein was determined according to the Lowry method. Equal amounts of proteins were separated in $10 \%$ SDS-polyacrylamide gel electrophoresis and transferred to polyvinylidene fluoride membranes. The membranes were blocked by $3 \%$ bovine serum albumin (BSA) in the Tris-buffered saline with Tween-20 (TBST) for $2 \mathrm{~h}$ at room temperature and then incubated with primary antibodies (Abcam, Cambridge, MA, USA) at $4^{\circ} \mathrm{C}$ overnight. The corresponding horseradish peroxidase-conjugated secondary antibodies were incubated for $2 \mathrm{~h}$ at room temperature. The protein bands were determined by electrochemical luminescence (ECL) and exposed by GeneGenius automatic gel imaging system (Syngene, Cambridge, UK). The experiment was repeated 3 times independently.

MTT (3-(4,5-Dimethylthiazol-2-yl)-2,5-diphenyltetrazolium bromide) assay. BGC-823 cells were seeded in 96-well microplates at a density of $0.2 \times 10^{4} /$ well for $0,12,24,36$ and $48 \mathrm{~h}$, respectively. MTT solution $(20 \mu \mathrm{l} ; 5 \mathrm{mg} / \mathrm{ml})$ was added into every well. Cells were cultured at $37^{\circ} \mathrm{C}$ and $5 \% \mathrm{CO}_{2}$ for $4 \mathrm{~h}$, followed by the addition of $100 \mu \mathrm{l}$ of solubilization solution into each well. The plates were kept in a dark room overnight, and the absorbance (A) at $570 \mathrm{~nm}$ was read by a Tecan Sunrise (Tecan, Männedorf, Switzerland).

Transmission electron microscopy. The 5- $\mathrm{mm}^{3}$ cells lumps generated by centrifugation were soaked in the $2.5 \%$ glutaraldehyde solution for $12 \mathrm{~h}$, washed using $0.1 \mathrm{~mol} / 1$ phosphate-buffered saline (PBS) three times and kept in PBS overnight at $4^{\circ} \mathrm{C}$. Then, the lumps were soaked in $1 \%$ osmium tetroxide acid $\left(\mathrm{OsO}_{4}\right)$ for $2 \mathrm{~h}$ and washed again, and incubated at $4^{\circ} \mathrm{C}$ overnight. The cells lumps were dehydrated with ethanol solutions step by step for $15 \mathrm{~min}$. Following dehydration, the lumps were washed by acetone twice, then soaked in the fluid which was mixed with the resin and an equal volume
A

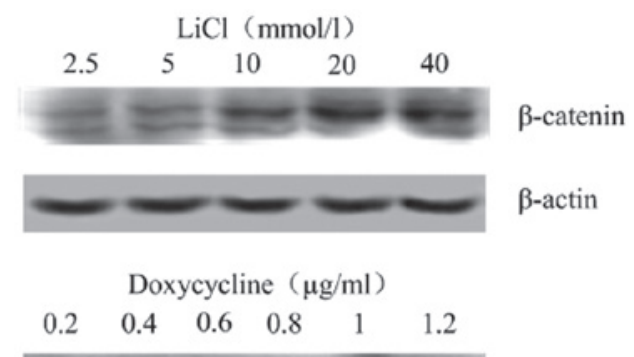

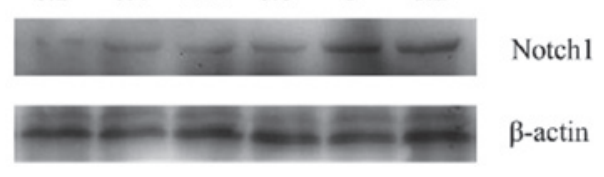

Figure 1. LiCl- or doxycycline-induced Wnt or Notch1 activation in BGC-823 cells. (A) BGC-823 cells treated with various concentrations of $\mathrm{LiCl}$ as indicated showed levels of $\beta$-catenin protein. (B) BGC-823 cells treated with various concentrations of doxycycline as indicated showed levels of Notch1 protein.

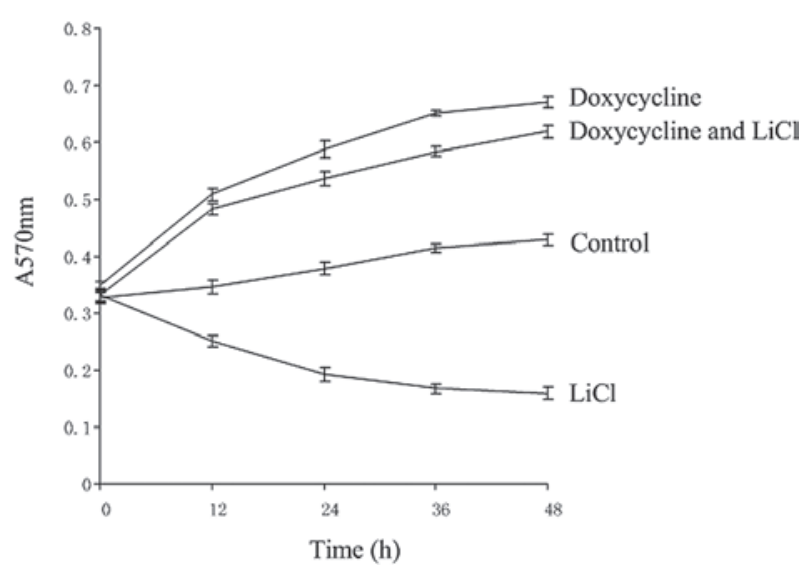

Figure 2. Growth of BGC-823 cells by MTT assay. Compared with control, the cell growth rate was markedly decreased in the presence of $1 \mu \mathrm{g} / \mathrm{ml}$ doxycycline $(\mathrm{P}<0.05$ vs. control), while it was significantly elevated in the presence of $10 \mathrm{mmol} / \mathrm{LiCl}(\mathrm{P}<0.05$ vs. control) and doxycycline and $\mathrm{LiCl}$ co-activated $(\mathrm{P}<0.05$ vs. control).

of acetone for $2 \mathrm{~h}$, and then soaked in pure resin overnight. Following embedding, cells lumps were incubated at $37^{\circ} \mathrm{C}$, $45^{\circ} \mathrm{C}, 60^{\circ} \mathrm{C}$ respectively for $24 \mathrm{~h}$. The lumps were fixed into pyramid shape to be cut into ultra-thin slices using the UC6 ultrathin slice machine (Leica, Wetzlar, Germany). The slices in nets were dyed and observed using transmission electron microscope (Carl Zeiss, Oberkochen, Germany).

Flow cytometry. BGC-823 cells were collected after various treatments by trypsinization, washed with PBS, fixed overnight in $70 \%$ ethanol at $4^{\circ} \mathrm{C}$, incubated for $30 \mathrm{~min}$ with $40 \mu \mathrm{g}$ propidium iodide (PI, Sigma) and $100 \mu \mathrm{g}$ RNase A (Sigma) in PBS and analyzed on a FACSCalibur flow cytometer (Becton-Dickinson, Mountain View, CA, USA). Collected data were analyzed by CellQuest Pro Analysis software.

Statistical analysis. Each group of experiments was repeated at least three times. Data were evaluated using the Statistics Software Package (Student's t-test or analysis of variance). $\mathrm{P}<0.05$ was considered to indicate a statistically significant difference. 
A
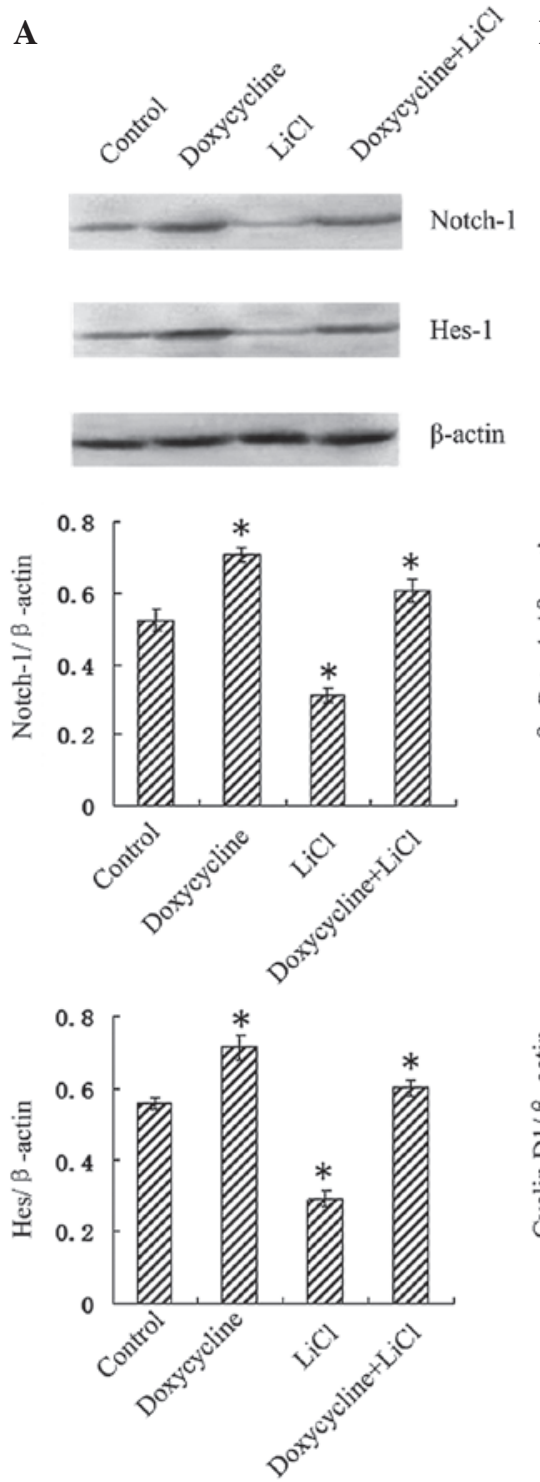

B
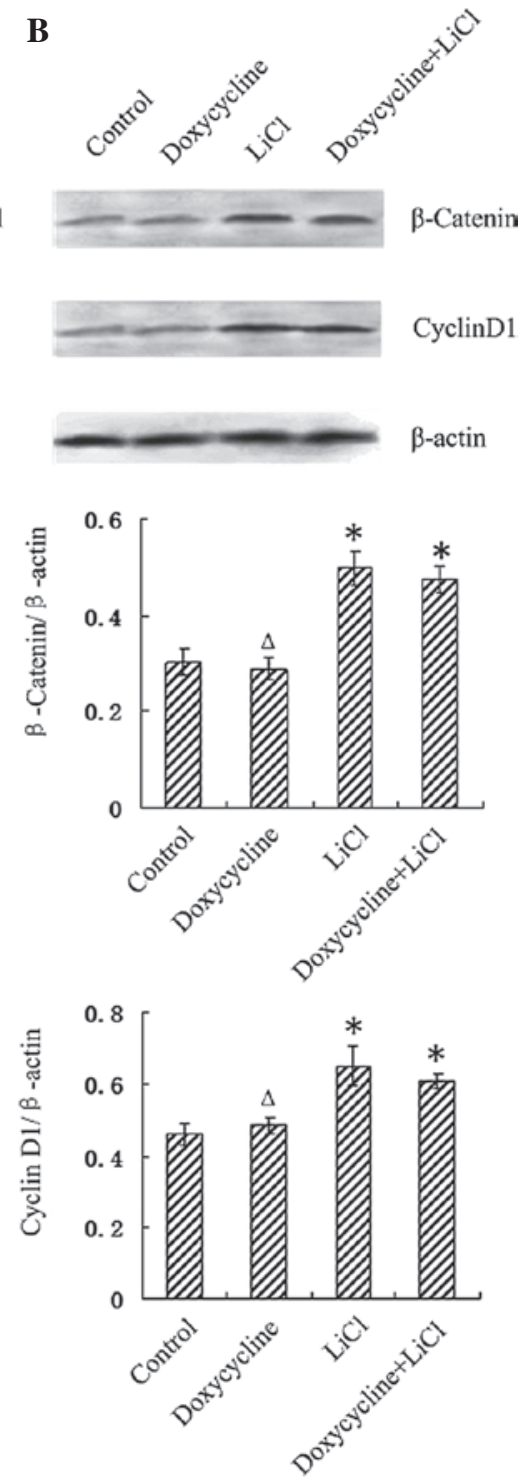

Figure 3. Expression of the key components of two signaling pathways in BGC-823 cells. (A) Western blot analysis of Notch1 and Hes1 expression in the presence of $1 \mu \mathrm{g} / \mathrm{ml}$ doxycycline and/or $10 \mathrm{mmol} / 1 \mathrm{LiCl}$. $\beta$-actin was used as an internal control (upper panel). Band intensities for Notch1 and Hes1 were quantified and normalized to $\beta$-actin level (middle and bottom panel). ${ }^{*} \mathrm{P}<0.01$ vs. control. (B) Western blot analysis of Notch1 and Hes1 expression in the presence of $1 \mu \mathrm{g} / \mathrm{ml}$ doxycycline and/or $10 \mathrm{mmol} / 1 \mathrm{LiCl}$. $\beta$-actin was used as an internal control (upper panel). Band intensities for $\beta$-catenin and cyclin D1 were quantified and normalized to $\beta$-actin level (middle and bottom panel). ${ }^{*} \mathrm{P}<0.01$ vs. control; ${ }^{\Delta} \mathrm{P}>0.05$ vs. control was added.

\section{Results}

Activation of Notch and Wht signaling pathways. BGC-823 cells were harvested at $24 \mathrm{~h}$ after treatment with different concentrations of $\mathrm{LiCl}$ and doxycycline. Western blot analysis showed that $\beta$-catenin and Notch1 were expressed in an activator concentration-dependent manner, and that $\beta$-catenin or Notch1 proteins were significantly increased by $10 \mathrm{mmol} / 1 \mathrm{LiCl}$ or $1 \mu \mathrm{g} / \mathrm{ml}$ doxycycline, respectively (Fig. 1). Compared with the control, cell proliferation was significantly inhibited when the Notch1 signaling pathway was activated, while cell proliferation was enhanced when the Wnt/ $\beta$-catenin signaling pathway was activated or when the Wnt and Notch pathways were coactivated (Fig. 2).

Expression of key components of two signaling pathways in BGC-823 cells. Firstly, the protein expression of Notch1 and the Notch target gene Hes1 were measured by western blot analysis using polyclonal antibodies against Notch1 (including epitopes of NICD) and Hes1. Upon activation of the Notch1 pathway by doxycycline or the activation of both Notch1 and Wnt pathways by doxycycline and $\mathrm{LiCl}$, the expression of Notch1 and Hes1 was significantly increased compared with the control, while it was reduced in LiCl-treated cells (Fig. 3A). Secondly, the protein expression of $\beta$-catenin and cyclin D1 in single or both activator-treated cells were detected. The expression levels of $\beta$-catenin and cyclin D1 were significantly increased in doxycycline-treated and co-activated cells (Fig. 3B).

Ultrastructural alterations of BGC-823 cells under Wnt and Notch co-activation. When Notch1 signaling was activated, the cell membrane microvilli were reduced, the nucleus atrophied and some vacuoles were observed in the cytoplasm of 

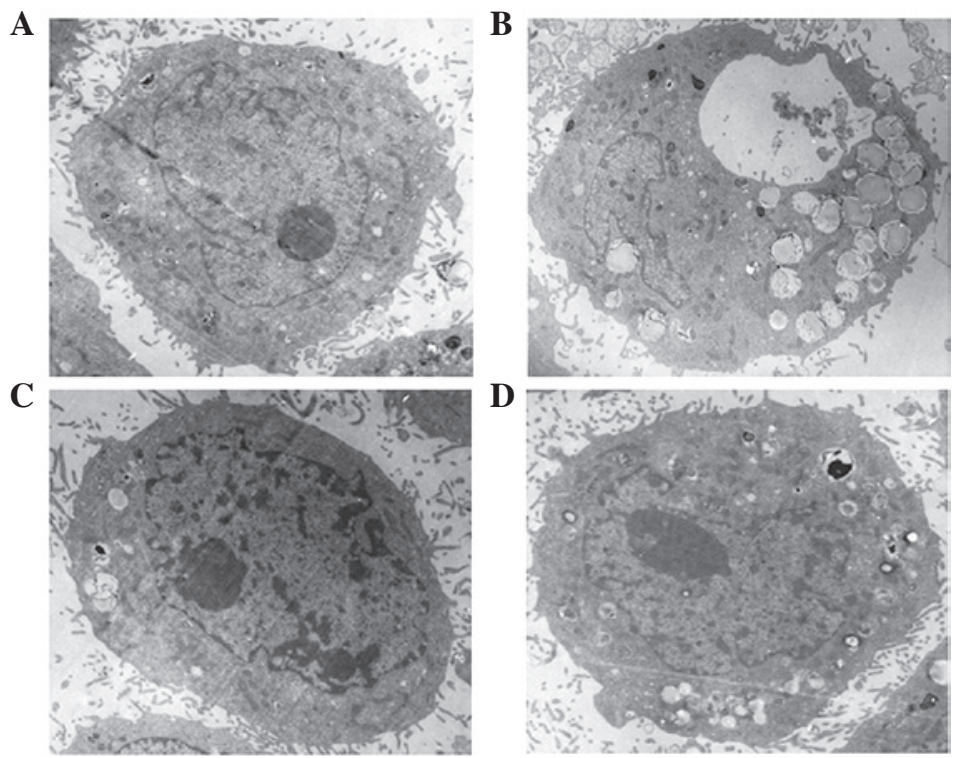

Figure 4. Ultrastructure of BGC-823 cells observed under a transmission electron microscope. (A) Morphology in the control (magnification, x3,000). (B) Ultrastructure of BGC-823 cells treated with $1 \mu \mathrm{g} / \mathrm{ml}$ doxycycline (magnification, $\mathrm{x} 3,000$ ); numerous vacuoles were observed in the cytoplasm. (C) Ultrastructure of BGC-823 cells treated with $10 \mathrm{mmol} / 1 \mathrm{LiCl}$; a limited number of vacuoles was observed in the cytoplasm (magnification, x 5,000 ). (D) Ultrastructure of BGC-823 cells with doxycycline and $\mathrm{LiCl}$ co-activation (magnification, x3,000); cell membrane microvilli were developed. Some vacuoles were observed in the cytoplasm.

A

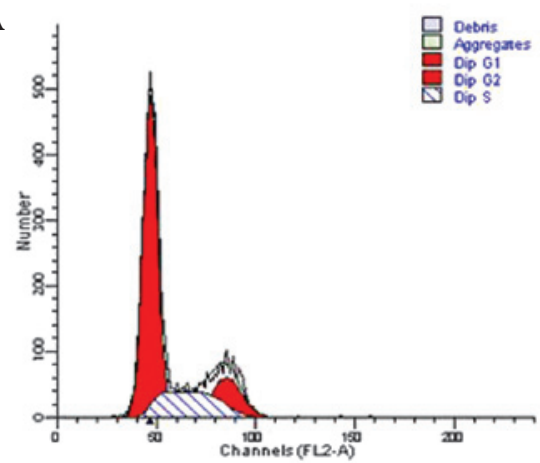

C

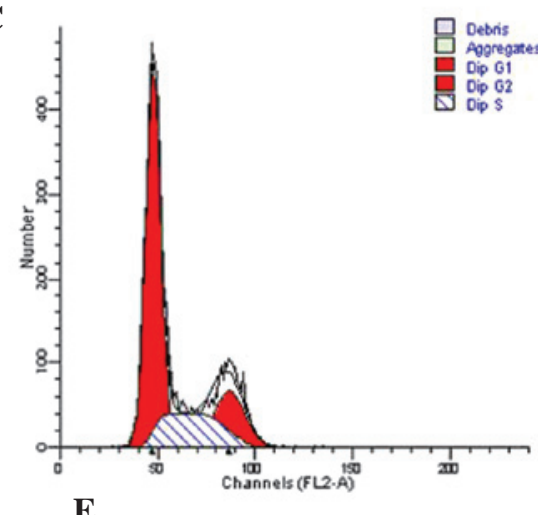

B

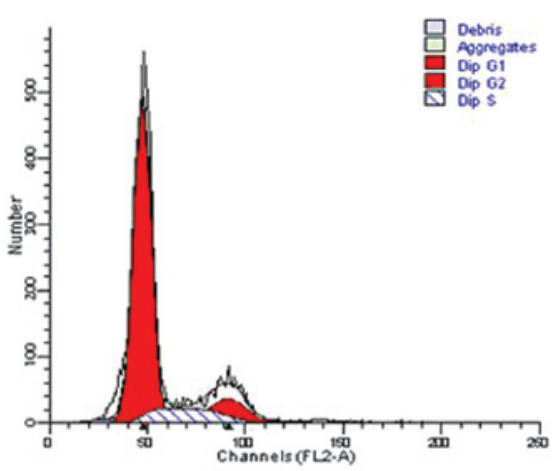

D

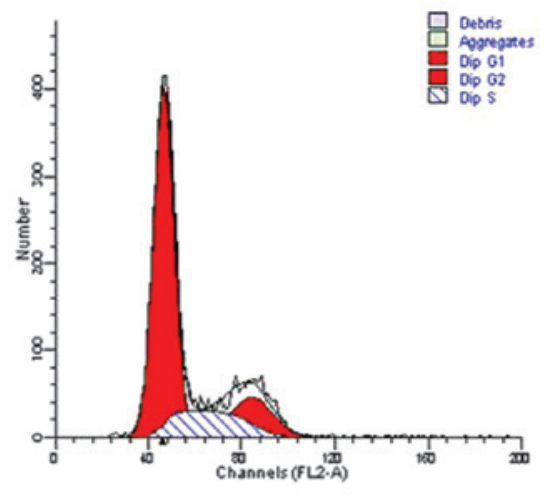

\begin{tabular}{lcllc}
\hline & Control & Doxycycline & LiCl & co-activators \\
\hline $\mathrm{G}_{1}$ phase & 63.11 & 75.44 & 60.04 & 66.80 \\
$\mathrm{~S}$ phase & 21.29 & $13.25^{* *}$ & $22.04^{* *}$ & $22.04^{*}$ \\
$\mathrm{G}_{2}$ phase & 15.60 & 11.31 & 17.92 & 17.92. \\
$\mathrm{~S} / \mathrm{G}_{1}$ ratio & 33.73 & $17.56^{* *}$ & $36.71^{* *}$ & $32.99^{*}$ \\
\hline
\end{tabular}

Figure 5. Apoptosis in BGC-823 cells by flow cytometry. After $24 \mathrm{~h}$ from transfection, cells were harvested for flow cytometric analysis of cell cycle distribution. (A) BGC-823 cells without treatment. (B) BGC-823 cells treated with $1 \mu \mathrm{g} / \mathrm{ml}$ doxycycline. (C) BGC-823 cells treated with $10 \mathrm{mmol} / 1 \mathrm{LiCl}$. (D) BGC-823 cells in the presence of $1 \mu \mathrm{g} / \mathrm{ml}$ doxycycline and $10 \mathrm{mmol} / \mathrm{L} \mathrm{LiCl}$. (E) The distribution of cells during the cell cycle phases. Three separate experiments were performed and data from one representative experiment are shown. 


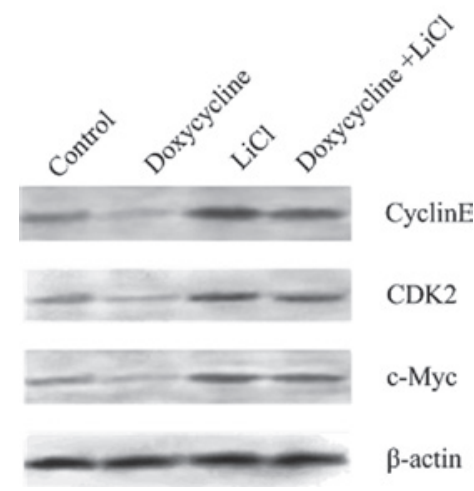

Figure 6. Expression analysis of Notch and Wnt signaling pathway target proteins in BGC-823 cells in the presence of $1 \mu \mathrm{g} / \mathrm{ml}$ doxycycline and/or $10 \mathrm{mmol} / \mathrm{l} \mathrm{LiCl}$. $\beta$-actin was used as an internal control.

cells (Fig. 4B). These data suggest that cell necrosis occurred when the Notch1 pathway was activated. When Wnt or both Wnt and Notch pathways were activated, we found that the membrane microvilli were developed, and that a limited number of vacuoles was observed in the cytoplasm (Fig. 4C and D). Cell membrane microvilli were developed and the organelles were normal. The nucleolus was clear in the control (Fig. 4A).

Cell cycle analysis of BGC-823 cells when Notch and Wnt were co-activated. Compared with the control, $\mathrm{G}_{1} / \mathrm{S}$ transition was blocked when Notch1 signaling was activated, while $G_{1} / S$ transition was promoted when $\mathrm{Wnt} / \beta$-catenin signaling was activated. The proportion of the cells in $\mathrm{S}$ phase in the coactivated cells was higher compared with the control, while lower than the group in which only the Wnt/ $\beta$-catenin signaling was activated (Fig. 5).

Expression of CDK2, cyclin E and c-Myc in BGC-823 cells under Wnt and Notch co-activation. The expression of cyclin E, CDK2 and c-Myc in activation of Notch1 signaling were significantly lower compared with the control, suggesting that Notch1 signaling inhibits cell proliferation by blocking the $\mathrm{G}_{1} / \mathrm{S}$ transition. When the Wnt pathway was activated by $\mathrm{LiCl}$, the expression of cyclin E, CDK2 and c-Myc was significantly increased, suggesting that $\mathrm{Wnt} / \beta$-catenin signaling promotes BGC-823 cell proliferation by advancing $G_{1} / S$ transition and accelerating the cell cycle process. When both Wnt and Notch1 were activated, the expression levels of cyclin E, CDK2 and c-Myc were significantly increased compared with the control, while they were lower compared with the expression levels when only the Wnt pathway was activated, suggesting that the Wnt/ $\beta$-catenin signaling had a certain antagonistic effect on Notch1 signaling (Fig. 6).

\section{Discussion}

In the present study, the effects of the activation of Notch1 pathway by doxycycline, the activation of Wnt pathway by $\mathrm{LiCl}$ and the co-activation of the two pathways were observed in BGC-823 cells. It was found that the activation of Wnt signaling overcomes the pro-apoptotic role of Notch in gastric cancer cells.
Firstly, the two pathways were triggered using doxycycline and $\mathrm{LiCl}$, respectively. Treatment with doxycycline, an activator of the Notch1 signaling pathway, resulted in higher expression levels of the Notch1 and Hes1 proteins. Treatment with $\mathrm{LiCl}$, an activator of the $\mathrm{Wnt} / \beta$-catenin signaling pathway, resulted in higher expression levels of the $\beta$-catenin and cyclin D1 proteins. CDK2-cyclin E complexes, phosphorylating the retinoblastoma protein, drive cells into the $\mathrm{S}$ phase of the cell cycle. The proto-oncogene c-Myc protein promotes cell proliferation and induces cytologic atypia, through binding to the specific DNA sequence. c-Myc also has a close association with the $G_{1} / S$ transition.

Compared with the control, when only the Notch1 signaling pathway was activated, the expression of $\beta$-catenin and cyclin D1 were stable, while the expression of cyclin E, CDK2 and c-Myc decreased, suggesting that the Notch1 signaling pathway had no marked effect on the Wnt/ $\beta$-catenin signaling pathway. The inhibition of cyclin E, CDK2 and $\mathrm{c}-\mathrm{Myc}$ resulted in cell cycle retardation and inhibited the proliferation of BGC-823 cells. When only the Wnt/ $\beta$-catenin signaling pathway was activated, the expression of Notch1 and Hes1 significantly decreased, while the expression of cyclin E, CDK2 and c-Myc increased, suggesting that the Notch1 signaling pathway may be regulated to some extent by the Wnt/ $\beta$-catenin signaling pathway. Previous studies have shown that Dsh has an antagonistic effect on the Notch1 signaling pathway by binding to the intracellular domain of Notch1 (28). The high levels of cyclin D1, cyclin E, CDK2 and c-Myc promote $G_{1} / S$ transition and the cell proliferation of BGC-823 cells. When the Notch1 and Wnt/ $\beta$-catenin signaling pathways were simultaneously activated, the expression of Notch1 and Hes1 was higher compared with the control, while it was lower compared with the group in which only the Notch1 signaling pathway was activated. The expression of $\beta$-catenin and cyclin D1 was higher compared with the control, while it was not different when only the Wnt/ $\beta$-catenin signaling was significantly activated. The expression levels of cyclin E, CDK2 and c-Myc were higher compared with the control, suggesting that the activated Wnt/ $\beta$-catenin signaling pathway was able to overcome the inhibitory effects of the Notch1 signaling pathway on cyclin E, CDK2 and c-Myc.

In conclusion, it was found that the Notch1 signaling pathway plays an inhibitory role in the process of BGC- 823 cell development. The activated Notch1 signaling inhibits the proliferation of BGC-823 cells by the downregulation of c-Myc, cyclin E and CDK2, while the highly regulated Wnt signaling cascade plays a key role during BGC-823 cell development. The activated $\mathrm{Wnt} / \beta$-catenin signaling promotes the proliferation of BGC-823 cells by the upregulation of c-Myc, cyclin D1, cyclin E and CDK2. Furthermore, Wnt/ $\beta$-catenin signaling had an antagonistic effect on the Notch1 signaling pathway. When the two signaling pathways were simultaneously activated, there was a combined effect of promoting the proliferation of BGC-823 cells by upregulating the expression of c-Myc, cyclin D1, cyclin E and CDK2.

Strong evidence indicates that the Wnt cascade constitutes the major driving force behind the proliferative potential of adenomas and adenocarcinomas of the stomach. Recent data indicate that active Notch signaling plays an important role in 
the maintenance of the undifferentiated state of gastric cells, suggesting that Notch may provide an alternative targeted-drug strategy for the treatment of gastric neoplastic diseases. A further study would be to explore the balance between the Wnt signaling cascade and Notch1 signaling pathway of gastric cancer cells.

\section{Acknowledgements}

The authors would like to thank Rongjian Su (Liaoning Medical University, Jinzhou, China) for reviewing and providing helpful advice for this manuscript. This project was supported by the Natural Science Foundation of Liaoning Province (no. 201102125).

\section{References}

1. Ushijima T and Sasako M: Focus on gastric cancer. Cancer Cell 5: 121-125, 2004.

2. Gonzalez CA, Sala N and Capella G: Genetic susceptibility and gastric cancer risk. Int J Cancer 100: 249-260, 2002.

3. Guo JL, Zheng SJ, Li YN, et al: Toxicarioside A inhibits SGC-7901 proliferation, migration and invasion via NF-kappaB/ bFGF signaling. World J Gastroenterol 18: 1602-1609, 2012.

4. El-Rifai W and Powell SM: Molecular biology of gastric cancer. Semin Radiat Oncol 12: 128-140, 2002.

5. Smith MG, Hold GL, Tahara E and El-Omar EM: Cellular and molecular aspects of gastric cancer. World J Gastroenterol 12 : 2979-2990, 2006.

6. Kang MH, Oh SC, Lee HJ, Kang HN, Kim JL, Kim JS and Yoo YA: Metastatic function of BMP-2 in gastric cancer cells: the role of PI3K/AKT, MAPK, the NF-kappaB pathway, and MMP-9 expression. Exp Cell Res 317: 1746-1762, 2011.

7. Maloum F, Allaire JM, Gagne-Sansfacon J, et al: Epithelial BMP signaling is required for proper specification of epithelial cell lineages and gastric endocrine cells. Am J Physiol Gastrointest Liver Physiol 300: G1065-G1079, 2011.

8. Martin J, Donnelly JM, Houghton J and Zavros Y: The role of sonic hedgehog reemergence during gastric cancer. Dig Dis Sci 55: 1516-1524, 2010.

9. Hsu KW, Hsieh RH, Huang KH, et al: Activation of the Notch1/ STAT3/Twist signaling axis promotes gastric cancer progression. Carcinogenesis 33: 1459-1467, 2012.

10. Radulescu S, Ridgway RA, Cordero J, et al: Acute WNT signalling activation perturbs differentiation within the adult stomach and rapidly leads to tumour formation. Oncogene: Jun 4, 2012 (Epub ahead of print). doi: 10.1038/onc.2012.224.
11. Kim TH and Shivdasani RA: Notch signaling in stomach epithelial stem cell homeostasis. J Exp Med 208: 677-688, 2011.

12. Sun Y, Gao X, Liu J, et al: Differential Notch1 and Notch2 expression and frequent activation of Notch signaling in gastric cancers. Arch Pathol Lab Med 135: 451-458, 2011.

13. Yeh TS, Wu CW, Hsu KW, et al: The activated Notch1 signal pathway is associated with gastric cancer progression through cyclooxygenase-2. Cancer Res 69: 5039-5048, 2009.

14. Katoh M: Notch ligand, JAG1, is evolutionarily conserved target of canonical WNT signaling pathway in progenitor cells. Int J Mol Med 17: 681-685, 2006.

15. Piazzi G, Fini L, Selgrad M, et al: Epigenetic regulation of Delta-Like1 controls Notch1 activation in gastric cancer. Oncotarget 2: 1291-1301, 2011.

16. Artavanis-Tsakonas S, Rand MD and Lake RJ: Notch signaling: cell fate control and signal integration in development. Science 284: 770-776, 1999.

17. Roy M, Pear WS and Aster JC: The multifaceted role of Notch in cancer. Curr Opin Genet Dev 17: 52-59, 2007.

18. Kadesch T: Notch signaling: the demise of elegant simplicity. Curr Opin Genet Dev 14: 506-512, 2004.

19. Barth AI, Nathke IS and Nelson WJ: Cadherins, catenins and APC protein: interplay between cytoskeletal complexes and signaling pathways. Curr Opin Cell Biol 9: 683-690, 1997.

20. Kikuchi A, Yamamoto $\mathrm{H}$ and Kishida S: Multiplicity of the interactions of Wnt proteins and their receptors. Cell Signal 19: 659-671, 2007.

21. Cajanek L, Ribeiro D, Liste I, Parish CL, Bryja V and Arenas E: Wnt/beta-catenin signaling blockade promotes neuronal induction and dopaminergic differentiation in embryonic stem cells. Stem Cells 27: 2917-2927, 2009.

22. Wang QM, Zhang Y, Yang KM, Zhou HY and Yang HJ: Wnt/ beta-catenin signaling pathway is active in pancreatic development of rat embryo. World J Gastroenterol 12: 2615-2619, 2006.

23. Zhang Y, Li XM, Zhang FK and Wang BE: Activation of canonical Wnt signaling pathway promotes proliferation and self-renewal of rat hepatic oval cell line WB-F344 in vitro. World J Gastroenterol 14: 6673-6680, 2008.

24. Prasad CP, Rath G, Mathur S, Bhatnagar D and Ralhan R: Potent growth suppressive activity of curcumin in human breast cancer cells: Modulation of Wnt/beta-catenin signaling. Chem Biol Interact 181: 263-271, 2009.

25. Larue L and Delmas V: The WNT/Beta-catenin pathway in melanoma. Front Biosci 11: 733-742, 2006.

26. Park JK, Song JH, He TC, Nam SW, Lee JY and Park WS: Overexpression of Wnt-2 in colorectal cancers. Neoplasma 56: 119-123, 2009.

27. Sergio LE and Kalaska JF: Systematic changes in motor cortex cell activity with arm posture during directional isometric force generation. J Neurophysiol 89: 212-228, 2003.

28. Hansson EM, Lendahl U and Chapman G: Notch signaling in development and disease. Semin Cancer Biol 14: 320-328, 2004. 